10

\title{
Роль границы раздела водная среда-твердое тело в передаче возбуждения кремния светом
}

\author{
() Д.И. Тетельбаум, ${ }^{1}$ В.С. Туловчиков, ${ }^{1}$ Ю.А. Менделева, ${ }^{1}$ Е.В. Курильчик, ${ }_{1}^{1}$ А.А. Никольская, ${ }^{1}$ А.В. Степанов ${ }^{2}$ \\ ${ }^{1}$ Национальный исследовательский Нижегородский государственный университет им. Н.И. Лобачевского, \\ 603950 Нижний Новгород, Россия \\ 2 Чувашская государственная сельскохозяйственная академия, \\ 428017 Чебоксары, Россия \\ e-mail: tetelbaum@phys.unn.ru
}

Поступило в Редакцию 30 мая 2017 г.

В окончательной редакции 29 апреля 2018 г.

Принято к публикации 17 марта2019 г.

Установлен эффект, заключающийся в том, что при облучении светом образца кремния происходит изменение свойств другого образца $\mathrm{Si}$, удаленного от первого на расстояния до нескольких сантиметров, если оба образца находятся в контакте с системами „фторопласт-водный раствор $\mathrm{NaCl}^{\circ}$ либо „содержащее натрий стекло-вода“. Результаты интерпретированы на основе ранее предложенной модели генерации гиперзвуковых волн, возбуждаемых светом в системе кремний-естественный оксид, и гипотезы о распространении гиперзвуковых волн вдоль границы раздела водная среда-твердое тело, стимулированном наличием кластеров $\mathrm{Na}^{+}-\left(\mathrm{H}_{2} \mathrm{O}\right)_{n}$.

Ключевые слова: световое возбуждение и распространение гиперзвуковых волн, естественный оксид кремния, водная среда, граница раздела, эффект дальнодействия.

DOI: 10.21883/JTF.2019.09.48070.2365

\section{Введение}

Необычные свойства поверхностных и граничащих с твердыми телами слоев воды и водных растворов давно привлекают внимание исследователей различного профиля [1-9]. Интерес к этой проблеме со стороны биомедицины и радиофизики был стимулирован работами, проведенными в Институте ИРЭ им. Котельникова, начатыми еще в прошлом веке под руководством акад. Н.Д. Девяткова и посвященными изучению роли электромагнитных волн крайне высокочастотного (КВЧ) диапазона в клеточных процессах, протекающих в живых организмах, а также по использованию таких волн в медицине [2]. Был сделан вывод о том, что данные процессы обусловлены свойствами водной среды, находящейся в контакте с клеточными мембранами [8]. Одним из интригующих фактов, обсуждавшихся в связи с данной проблемой, является аномально глубокое проникновение действия облучения по сравнению с глубиной проникновения волн КВЧ. Отмечалось, что электромагнитное КВЧ-излучение, генерируемое клеточной мембраной, может преобразовываться в акустическиегиперзвуковые волны (ГВ) (термин „гиперзвуковые“ здесь и далее характеризует не скорость распространения волн, а частоту).

Нами установлен эффект, в котором, согласно предложенному механизму, играют роль два явления: вопервых, генерация ГВ при облучении кремния светом и, во-вторых, стимулированное наличием ионов натрия распространение ГВ по границе раздела водная среда-твердое тело. Обсуждается междисциплинарное значение данного эффекта.

\section{Методика}

Суть установленного эффекта состоит в том, что при определенных условиях облучения светом образца кремния происходит изменение свойств другого кремниевого образца, который облучению не подвергался и был удален от первого на расстояния до нескольких сантиметров.

Для фиксации изменения свойств кремния использовался метод микротвердости $(H)$, обладающий высокой чувствительностью к дефектной структуре [10]. Использование данного метода обусловлено его экспрессностью, что позволяет за приемлемое время получать достаточно большой объем информации об условиях проявления изучаемого эффекта и влиянии на него различных факторов. Вместе с тем, как было нами показано, изменение микротвердости при облучении кремния светом или ионами сопровождается изменением и других структурно-чувствительных свойств твердого тела [11-13] и потому служит надежным индикатором таких изменений.

Используемая нами методика измерения микротвердости детально описана в [14]. Она заключалась в измерении размеров отпечатков алмазной пирамидки (индентора) до и после воздействия с применением микротвердомера ПМТ-3. В настоящей работе процедура измерений по сравнению с описанной в [14] была модернизирована путем выведения изображений отпечатков на монитор компьютера с помощью фотокамеры, что позволяло облегчить процедуру и уменьшить погрешность измерений. 


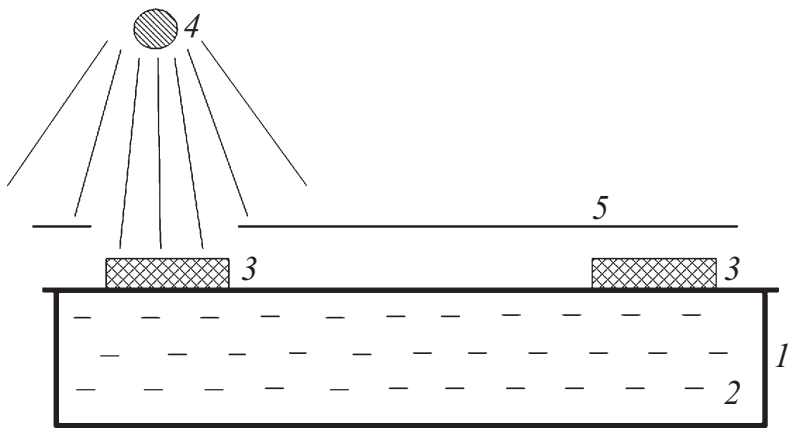

Рис. 1. Схема экспериментов (для варианта 1): $1-$ фторопластовая кювета; 2 - раствор $\mathrm{NaCl}$ в воде; 3 - образцы кремния; 4 - источник света; 5 - диафрагма.

Оптимальные условия измерения микротвердости выбраны на основе нашего предыдущего опыта, накопленного при изучении влияния ионного и светового облучений на свойства кремния (так называемого „эффекта дальнодействия“ (ЭД), [15-18] и ссылки там). Нагрузка на индентор составляла $0.7 \mathrm{~N}$, при этом глубина отпечатков составляла $\sim 1 \mu \mathrm{m}$. Каждый раз на образце создавали по 5 отпечатков, и обе диагонали отпечатка измерялись дважды; таким образом, при расчете $H$ усреднение проводилось по 20 значениям.

Исследуемый эффект наблюдался в двух вариантах экспериментов.

Вариант 1. Использовалась прямоугольная фторопластовая кювета с размерами (в плане) $20 \times 3 \mathrm{~cm} \mathrm{c}$ толщинами крышки и дна по $1 \mathrm{~mm}$ и с расстоянием между крышкой и дном $1 \mathrm{~mm}$. Кювета заполнялась водным раствором $\mathrm{NaCl}$ так, чтобы раствор находился в непосредственном контакте с крышкой. На крышку помещались два образца кремния марки КДБ-1 (111) на некотором расстоянии друг от друга (порядка нескольких сантиметров). Один из образцов (,источник“) облучался светом 25-ватной лампы накаливания от осветителя к микроскопу, нить которой (если специально не указано) находилась на расстоянии $7 \mathrm{~cm}$ от образца. Другой образец (,приемник“) в это время находился в тени (рис. 1). Размеры образцов варьировали, но в большинстве случаев были много меньше расстояния между ними. Длительность облучения также варьировалась (там, где специально не оговорено, она составляла 100 s). До и после облучения проводились измерения микротвердости образца-приемника. При этом наколы индентора производились после прекращения засветки с задержкой не более $3 \mathrm{~min}$.

Вариант 2. Пластина технического стекла (с концентрацией натрия $\sim 10 \mathrm{wt} . \%$ ) толщиной $5 \mathrm{~mm}$ помещалась на дно пластикового или стеклянного сосуда с водой. Образцы кремния („источник“ и ,приемник“) помещались на верхнюю поверхность пластины. В остальном эксперименты проводились так же, как в варианте 1. Не было замечено существенной разницы результатов для двух случаев, в одном из которых уровень воды был выше уровня верхней поверхности пластины, а в другом - ниже. Во втором случае микрозазор между дном сосуда и стеклянной пластиной был (благодаря капиллярным силам) заполнен водой (иначе эффект отсутствовал).

\section{Результаты и их обсуждение}

Основным результатом экспериментов является изменение микротвердости $H$ образца-приемника при облучении удаленного от него образца-источника. Это свидетельствует о возникновении сигнала, идущего от источника и действующего на материал приемника. В контрольных опытах, когда образец-источник отсутствовал, либо отсутствовала водная среда, изменения $H$ образца-приемника не происходило.

В варианте 1 измерена зависимость модуля относительного изменения микротвердости $(\Delta H / H)$ от расстояния между образцами (рис. 2). (Статистическая погрешность измерения $\Delta H / H$ здесь и далее составляла $\pm 2 \%$.)

Если образец-приемник помещался не на крышке, а под кюветой, находясь с ней в контакте (в том числе непосредственно напротив образца-источника), величина $\Delta H / H$ в пределах погрешности была нулевой. Отсюда следует, что изменение микротвердости приемника связано с распространением сигнала вдоль границы водной среды с твердым телом, в данном варианте - фторопластом, тогда как в перпендикулярном направлении (вдоль нормали к поверхности) сигнал практически полностью затухает, не доходя до приемника, либо его амплитуда становится ниже порога чувствительности.

В варианте 2 был обнаружен пороговый характер увеличения максимальной дальности распространения сигнала с ростом интенсивности облучения: при превышении некоторого порога интенсивности (регулируемой путем изменения расстояния $r$ нити лампы от образца) дальность распространения резко возрастает; при этом, по крайней мере вплоть до расстояния $R=15 \mathrm{~cm}$ между

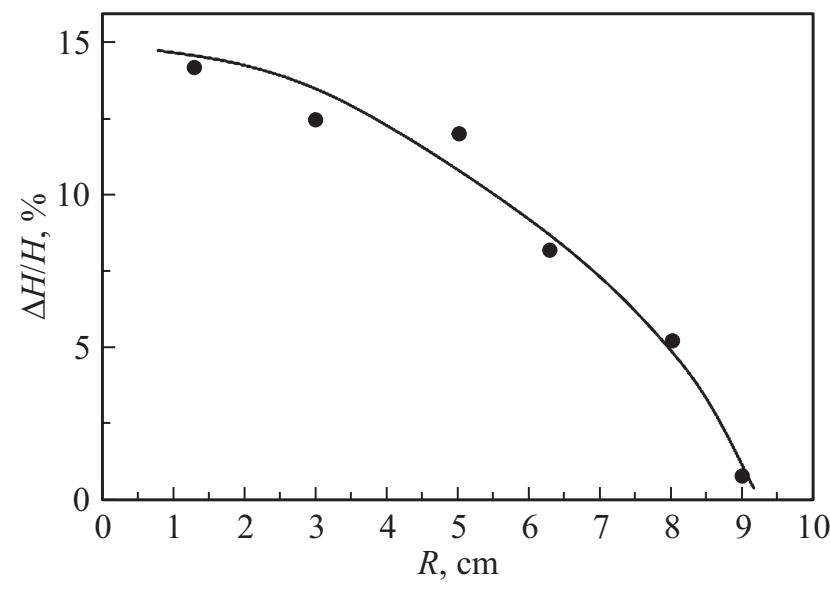

Рис. 2. Зависимость модуля относительного изменения микротвердости „образца-приемника“ от расстояния до „образцаисточника“ (для варианта 1). 


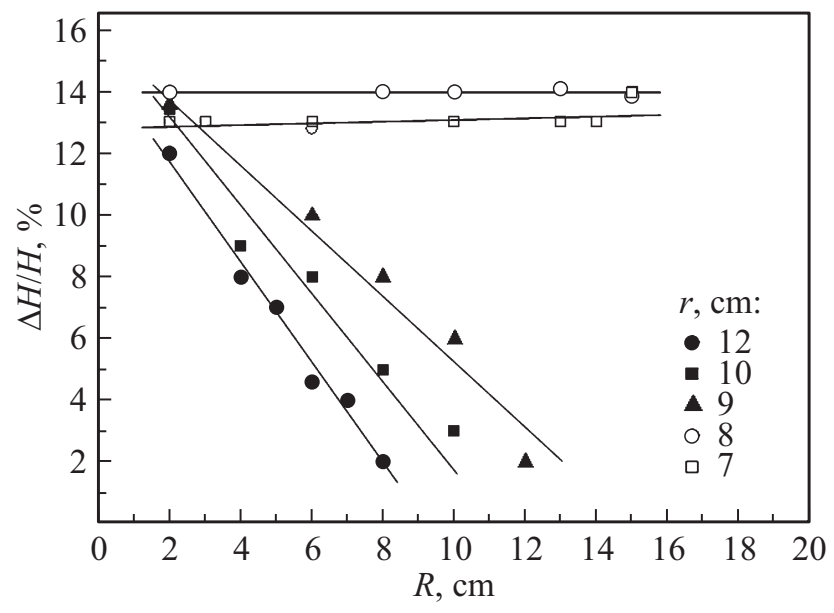

Рис. 3. Зависимость модуля относительного изменения микротвердости „образца-приемника“ от расстояния до „образца-источника“ при различных расстояниях последнего до источника света (различных интенсивностях облучения) (для варианта 2).

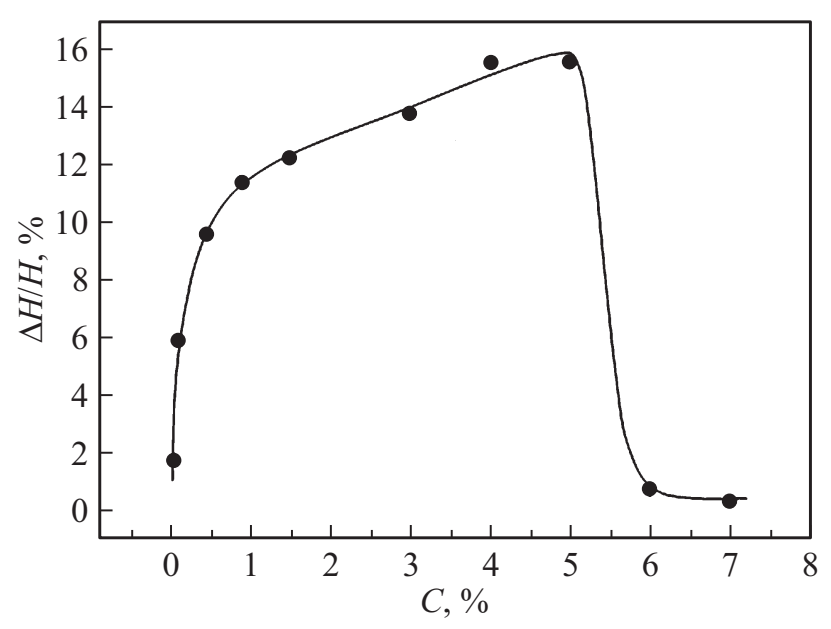

Рис. 4. Зависимость модуля относительного изменения микротвердости „образца-приемника“ при облучении светом „образца-источника“от концентрации $\mathrm{NaCl}$ в растворе (для варианта 1).

образцами, величина $\Delta H / H$ становится в пределах погрешности постоянной (рис. 3).

Критически важной особенностью эффекта является влияние ионов натрия. В варианте 1 эффект не имел места при использовании дистиллированной воды или раствора с концентрацией $\mathrm{NaCl}$ менее 0.1 wt.\% $(\mathrm{NaCl}$ при растворении почти полностью диссоциирует). Эффект практически отсутствовал и в том случае, когда концентрация $\mathrm{NaCl}$ была равна $6 \mathrm{wt} . \%$ и более. В интервале $0.1-5$ wt.\% величина $\Delta H / H$ монотонно возрастает (рис. 4). В варианте 2 эффект проявлялся и при использовании дистиллированной воды. В этом случае, очевидно, играют роль ионы $\mathrm{Na}^{+}$, содержащиеся в стекле. Действительно, при замене технического стекла на плавленый кварц (не содержащий натрия) эффект при использовании дистиллированной воды отсутствовал и проявлялся в этом случае лишь при использовании раствора.

Далее обсудим два основных вопроса:

1. Каковы природа и механизм генерации сигнала, ответственного за изменение микротвердости образца-приемника?

2. Каков механизм распространения сигнала вдоль границы раздела водная среда-твердое тело?

При ответе на первый вопрос мы имеем возможность опираться на богатый опыт, накопленный при изучении упомянутого выше ЭД ([15-18] и ссылки там). Он заключается [15-19] в аномально глубоком проникновении в твердое тело зоны влияния энергетических потоков, действующих на поверхность. В частности, нами было обнаружено, что под влиянием облучения светом поверхности не слишком толстого образца происходит изменение свойств слоев, прилегающих к противолежащей стороне образца. Этот эффект весьма трудно было объяснить каким-либо иным способом, кроме трансформации системы дефектов твердого тела под действием упругих волн, генерируемых при участии естественного оксида (ЕО), имеющегося на поверхности облучаемого образца. Удаление ЕО непосредственно перед воздействием всегда приводило к тому, что эффект не проявлялся или был весьма слабым.

В $[15,20]$ была предложена модель ЭД, которую мы используем для интерпретации описанного здесь эффекта. Ее основные положения заключаются в следующем.

При облучении твердого тела, покрытого ЕО, имеет место возбуждение электронов, локализованных на ловушках в ЕО, и пространственное перераспределение электронов, что вызывает возникновение или изменение внутреннего электрического поля. Процесс перераспределения электронов носит циклический (автоколебательный) характер, что приводит, благодаря пьезоэлектрическим свойствам ЕО, к генерации акустических колебаний и акустических волн. Последние проникают в объем твердого тела и вызывают модификацию в нем системы дефектов, в том числе на стороне, противоположной облучаемой. Эту модификацию мы и фиксируем путем измерения микротвердости либо другими способами.

Исходя из литературных данных по зависимости поглощения акустических волн в кремнии от частоты [21] и измерив относительное изменение микротвердости на обратной стороне образца кремния от его толщины, мы оценили характерную частоту волн, которая оказалась по порядку величины равной $10^{10}-10^{11} \mathrm{~Hz}$, что соответствует для электромагнитных волн диапазону крайне высоких частот (КВЧ), а для акустических - диапазону частот ГВ. Часть положений данной модели была подтверждена нами путем компьютерного моделирования методом молекулярной динамики [22].

Сушественно, что ЭД проявляется при облучении не только одиночных (монолитных) образцов, но и стопок, составленных из двух и более образцов [17]. Отсюда следует важный вывод: возмущение, индуцированное 

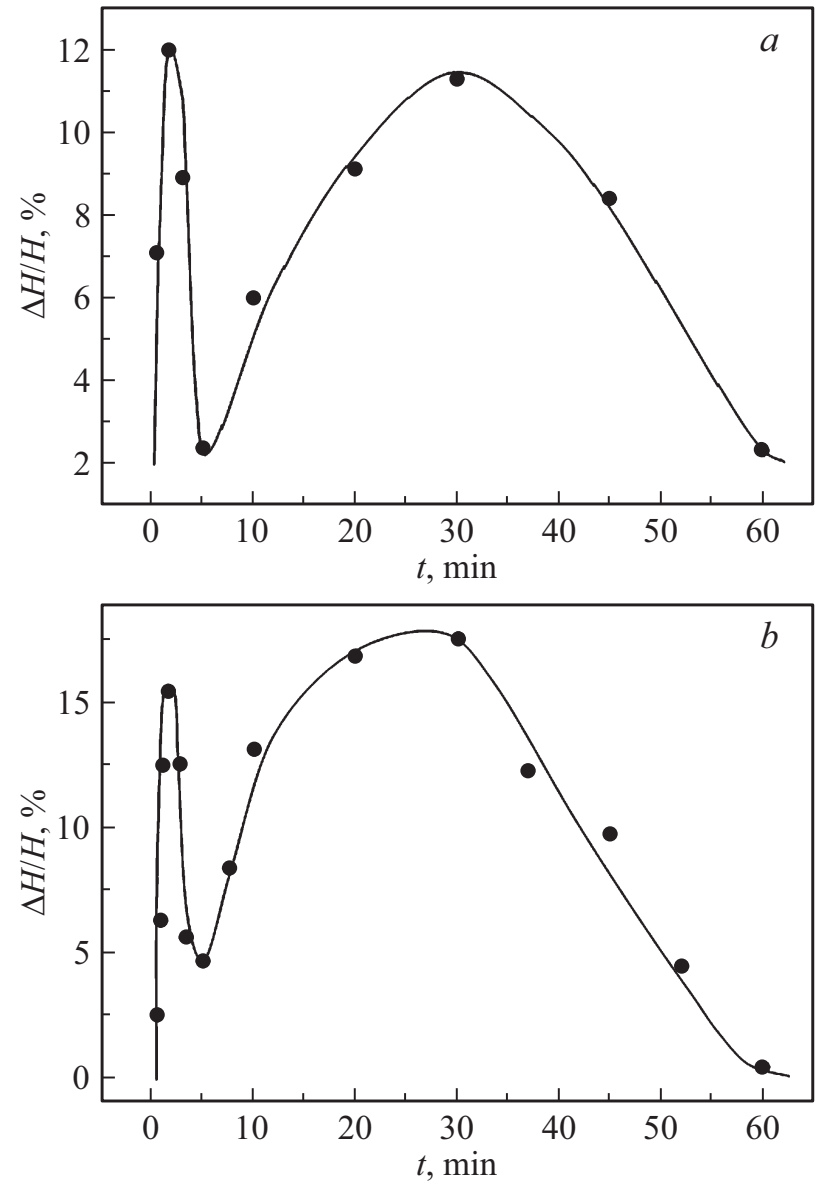

Рис. 5. Зависимость модуля относительного изменения микротвердости кремния от длительности облучения: $a-$ для одиночного образца; $b$ - для „образца-приемника““ (вариант 1).

облучением, может проникать через границы раздела конденсированных сред, в частности, через границу раздела твердого тела и водной среды.

Сказанное дает ключ для ответа на первый из поставленных выше вопросов - о вероятном механизме генерации сигнала (возбуждения) при облучении светом образца-источника. Когда этот сигнал достигает образцаприемника, он вызывает в нем качественно такие же изменения структуры и свойств, что и в случае облучения одиночных образцов или стопок. О единой природе сигнала, ответственного за ЭД при облучении одиночных образцов или стопок и за рассматриваемый здесь эффект, свидетельствуют следующие эксперименты. Во-первых, если в качестве образца-источника или образца-приемника используются образцы, с которых перед облучением был удален ЕО, то эффект отсутствует. Как уже сказано, такая же закономерность имеет место и при облучении монолитных образцов и стопок. Во-вторых (и это наиболее показательный факт), зависимость $\Delta H / H$ для образца-приемника от длительности облучения образца-источника имеет практически такой же вид, что и аналогичная зависимость при облучении одиночного образца (рис. 5). Это означает, что измене- ния структуры и свойств приемника происходят „в унисон“с с изменениями в образце-источнике. В-третьих, как и при облучении светом одиночных образцов, величина $\Delta H / H$ релаксирует в течение нескольких десятков минут (эти данные здесь не приведены).

Обратимся теперь ко второму вопросу - о механизме распространения сигнала на аномально большие расстояния. Выше указывалось, что в случае, когда образец-приемник расположен под фторопластовой кюветой (непосредственно напротив образца-источника), в нем не наблюдается изменений $H$; значит, ГВ до него практически не доходят. Действительно, согласно данным [23], для ГВ с частотой $\sim 10^{10} \mathrm{~Hz}$ коэффициент поглощения в воде составляет $\sim 3 \cdot 10^{4} \mathrm{~cm}^{-1}$; тогда уже на расстояниях порядка нескольких микрометров ГВ должны были бы практически полностью поглотиться. Поэтому мы вправе допустить, что распространение ГВ вдоль границы водной среды с фторопластом или содержащим натрий стеклом происходит с аномально низким коэффициентом поглощения. Это допущение не противоречит данным $[1,8]$, в соответствии с которыми поверхностные слои воды, а также границы раздела воды и твердого тела обладают особыми свойствами, отличными от объемных. В нашем случае следует дополнительно учесть роль натрия, ионы которого образуют кластеры $\mathrm{Na}^{+}-\left(\mathrm{H}_{2} \mathrm{O}\right)_{n}$ с размером порядка $1 \mathrm{~nm}$ [9].

Исходя из сказанного, предлагаем следующий сценарий распространения ГВ вдоль границы раздела водной среды с твердым телом.

Для варианта 1. Присутствующие в воде вблизи границы раздела с фторопластом кластеры $\mathrm{Na}^{+}-\left(\mathrm{H}_{2} \mathrm{O}\right)_{n}$ под действием электростатического взаимодействия между дипольным моментом кластеров и поляризованными молекулами граничного слоя фторопласта приобретают преимущественную ориентацию. (Поляризация молекул фторопласта может происходить за счет того, что приповерхностный слой воды, согласно данным [1], имеет положительный заряд). ГВ, проникающие через крышку кюветы в водный раствор, взаимодействуя с ориентированными кластерами, вызывают их вынужденные колебания. Кластеры становятся источниками вторичных волн, которые, в свою очередь, действуют на соседние кластеры. Если среднее расстояние между кластерами меньше характерной длины затухания ГВ, такой (эстафетный) механизм может обеспечить передачу сигнала на достаточно большие расстояния: пограничный слой водного раствора служит для ГВ своеобразным волноводом. При концентрациях $\mathrm{NaCl}$, равных 1-5wt.\%, среднее расстояние между ионами $\mathrm{Na}^{+}$ составляет $\sim 1 \mathrm{~nm}$. Коэффициент поглощения ГВ в воде равен $3 \cdot 10^{4} \mathrm{~cm}^{-1}$ при частоте $10^{10} \mathrm{~s}^{-1}$ и $3 \cdot 10^{6} \mathrm{~cm}^{-1}$ при частоте $10^{11} \mathrm{~s}^{-1}$ [23]. Отсюда легко оценить, что в нашем случае условие отсутствия значительного затухания ГВ в промежутках между кластерами для волн с частотами порядка $10^{10}-10^{11} \mathrm{~s}^{-1}$ выполняется. С указанной точки зрения резкое снижение величины $\Delta H / H$ при высоких концентрациях $\mathrm{NaCl}$ (рис. 4) можно 
объяснить тем, что, когда среднее расстояние между кластерами приближается к величине диаметра кластеров, последние перестают играть роль индивидуальных излучателей вторичных ГВ, и тогда описанный выше сценарий распространения волн теряет силу.

Для варианта 2. Роль центров зарождения кластеров $\mathrm{Na}^{+}-\left(\mathrm{H}_{2} \mathrm{O}\right)_{n}$ играют ионы натрия, входящие в состав стекла и расположенные вблизи поверхности, граничащей с водой. Не исключен также переход части ионов из стекла в пограничный слой воды (растворение). В остальном все приведенные рассуждения остаются в силе.

До сих пор мы обсуждали вопрос о распространении акустических (гиперзвуковых) волн. Между тем если генерация ГВ обусловлена переменным электрическим полем, то возникает вопрос: не могут ли сигналом, передающим возбуждение, служить непосредственно электромагнитные КВЧ-волны? Для ответа на этот вопрос был поставлен следующий опыт (в варианте 1): между кристаллом-источником и фторопластом при облучении был оставлен воздушный зазор (толщиной $\sim 1 \mathrm{~mm}$ ). Гиперзвук с частотой $\sim 10^{10}-10^{11} \mathrm{~Hz}$ не может проникать через такой зазор (тогда длина волны ГВ в воздухе оказалась бы меньше расстояния между молекулами воздуха, что лишено физического смысла); в то же время для электромагнитной волны зазор не является преградой. Опыт показал, что при наличии зазора эффект не наблюдается, и это дает на поставленный вопрос отрицательный ответ. Однако нельзя утверждать, что электромагнитные волны КВЧ вообще не играют роли в распространении сигнала. Действительно, если кластеры обладают дипольным моментом, то их акустические колебания должны порождать вторичные электромагнитные волны, которые действуют на соседние кластеры, те излучают акустические волны и т.д. В этом случае можно говорить о распространении не чисто акустических, а электроакустических волн (аналогично электроакустическим волнам, роль которых обсуждалась в случае медико-биологических исследований с КВЧ-излучением [2]).

Далее обсудим вопрос о том, насколько состоятельна предложенная модель с точки зрения достаточности амплитуды генерируемых ГВ для того, чтобы вызвать наблюдаемые изменения микротвердости. Микротвердость претерпевает изменения, если дислокации, образующиеся под действием индентора [10], встречают на своем пути дополнительные стопоры или изменяется концентрация стопоров. Стопорами могут служить точечные дефекты, например, вакансии или собственные междоузельные атомы, а также их комплексы. Одним из возможных механизмов, приводящих к инжекции таких дефектов в приповерхностный слой $\mathrm{Si}$ под действием ГВ, является механизм „вакансионного насоса“, предложенный В.П. Алехиным [24]: при переменной механической нагрузке в фазе сжатия происходит „накачка“ вакансий с поверхности, а в фазе разгрузки или смены знака напряжения - их сток в объем образца. Из данных [24] следует, что амплитуда напряжения $\sim 1 \mathrm{GPa}$ вызывает изменение концентрации вакансий $\sim 10^{24} \mathrm{~m}^{-3}$. Согласно [10], этого с запасом достаточно для существенного изменения микротвердости. Используя результаты наших молекулярно-динамических расчетов [22], получаем, что амплитуда ГВ $\sim 1 \mathrm{GPa}$ при облучении образца кремния, покрытого ЕО, вполне достижима. Правда, соотношение между амплитудой ГВ, генерируемой ЕО в образце-источнике, и амплитудой ГВ, достигающей поверхности образца-приемника, пока не известно. Тем не менее приведенная оценка демонстрирует принципиальную возможность интерпретации, основанной на описанной модели.

Представляет интерес также оценка соотношения между энергией, запасенной в образце-приемнике при „накачке“ дополнительных дефектов (для определенности - вакансий), и той энергией, которую получает образец-источник за время облучения. Предположим, что инжектированные вакансии распределены в слое толщиной $h$. Тогда запасенная энергия $E_{1}$ составляет

$$
E_{1}=n_{V} h S_{1} E_{V}
$$

где $n_{V}-$ концентрация вакансий, $S_{1}-$ площадь образца-приемника $\left(\sim 1 \mathrm{~cm}^{2}\right), E_{V}-$ энергия образования вакансии $(3.7 \mathrm{eV}[25])$. В качестве величины $h$ разумно принять глубину деформируемого индентором материала, которая примерно на порядок превышает глубину отпечатка [10]. В нашем случае имеем $h \approx 10^{-3} \mathrm{~cm}$. Тогда из (1) получаем $E_{1} \sim 10^{-3} \mathrm{~J}$. С другой стороны, лучистая энергия $E_{2}$, которую получает кристалл-источник за характерное время облучения $(t=100 \mathrm{~s})$, равна

$$
E_{2}=P t \alpha S_{2} / 4 \pi r^{2},
$$

где $r$ - характерное расстояние от нити лампы до образца-источника $(r=7 \mathrm{~cm}), P-$ мощность лампы $(P=25 \mathrm{~W}), S_{2}$ - площадь образца-источника $\left(\sim 1 \mathrm{~cm}^{2}\right)$, $\alpha$ - доля потребляемой лампой накаливания энергии, расходуемой на излучение $(\alpha>0.1$ [26]). (При $r=7 \mathrm{~cm}$ нить лампы можно рассматривать как точечный источник света). Из (2) получаем $E_{2} \sim 1 \mathrm{~J}$, что на 3 порядка превышает значение $E_{1}$. Таким образом, наша модель не приводит к явному противоречию и с этой точки зрения, даже если учесть, что лишь малая доля получаемой образцом лучистой энергии преобразуется в энергию ГВ.

\section{Заключение}

Полученные результаты на первый взгляд представляются странными. Однако приведенные зависимости неоднократно проверялись и неизменно демонстрировали полную воспроизводимость, что не дает оснований сомневаться в объективном существовании эффекта. В пользу его объективности свидетельствуют также хорошо выраженный регулярный (одномодовый либо двухмодовый) характер полученных зависимостей (рис. 2-5) 
и закономерное исчезновение эффекта при нарушении определенных условий, например, при удалении ЕО или отсутствии водной среды.

При интерпретации эффекта мы ограничились качественными соображениями и приближенными оценками, не претендующими на роль строгого теоретического описания и носящими скорее эвристический характер. Следует признать, что на данном этапе некоторые обнаруженные закономерности не просто объяснить даже качественно. Например, интригующим и пока трудно объяснимым фактом является пороговый характер увеличения дальности распространения эффекта с ростом интенсивности облучения (рис. 3). Отсутствие изменения $\Delta H / H$ в зависимости от расстояния между образцами при большой интенсивности, т. е. практически полное исчезновение „геометрического“ ослабления действия сигнала, наводит на мысль о резком изменении диаграммы направленности излучения ГВ с ростом интенсивности. Если при малой интенсивности излучение ГВ, повидимому, близко к изотропному (в плоскости границы раздела сред), то при большой интенсивности оно, возможно, становится направленным на образец-приемник (азимутальное положение приемника при этом варьировалось и не влияло на результат). Другими словами, при высокой интенсивности образец-источник как бы „чувствует“ положение образца-приемника. Это невозможно без наличия обратной связи в системе.

Изучение природы эффекта требует проведения дополнительных исследований, в частности, применения компьютерного моделирования типа молекулярной динамики и/или квантовой химии (с привлечением суперкомпьютерных технологий, как это было нами реализовано при изучении механизма ЭД в твердых телах [22]).

Независимо от интерпретации обнаруженный эффект представляет несомненный фундаментальный и практический интерес, носящий междисциплинарный характер. Он поднимает новые проблемы в области физики взаимодействия излучений с твердыми телами: акцентирует внимание на роли поверхностных оксидов, на возможность возбуждения автоколебательных процессов при стационарных воздействиях и др. Обнаруженные закономерности эффекта подкрепляют акустическую модель ЭД при облучении твердых тел $[15,20]$. Так как ЭД наблюдался не только для $\mathrm{Si}$, но и для многих других материалов, а также при различных способах возбуждения [11-18], интересно проверить это и в нашем случае.

Для специалистов, работающих в области исследования аномальных свойств воды и водных растворов [1], эффект интересен в связи с проблемой интерфейсных явлений, а также изучения роли кластерного строения воды и водных растворов $[1,5,9]$. Если изложенные выше модельные представления подтвердятся, то рассматриваемый эффект послужит стимулом для более детального изучения свойств межфазных границ жидкость-твердое тело $[1,3,8]$. Для акустики, радиофизики и электроники важен аспект эффекта, связанный с распространением волн КВЧ-диапазона в гетерогенных средах, содержащих наноразмерные неоднородности.
Особый интерес эффект представляет для специалистов в области медико-биологических применений КВЧизлучений, поскольку он имеет много общего с акустоэлектрическими явлениями в живых организмах $[2,3,6,8]$. Роль водной среды в последних играют такие жидкости, как кровь, лимфа, цитоплазма; роль твердого тела клеточные мембраны (обладающие пьезоэлектрическими свойствами [2]); роль фактора, запускающего процесс генерации волн, которую в нашем случае играет поток света, в живых организмах могут играть потоки энергии, связанные с процессами обмена веществ [2]. Не исключено также, что простая и экспрессная методика, используемая нами, окажется полезной в медикобиологических экспериментах, например, для генерации ГВ без привлечения специальной дорогостоящей аппаратуры, при изучении влияния различных биологических сред как проводников электроакустических колебаний и т.д.

Таким образом, авторы считают необходимым обратить внимание специалистов различных профилей на существование описанного эффекта и указать на важность изучения возможности его практических применений.

\section{Конфликт интересов}

Авторы заявляют, что у них нет конфликта интересов.

\section{Список литературы}

[1] Pollack G.H. The fourth phase of water. SEATTLE WA, USA.: Ebner and Sons Publishers, 2013. 359 p.

[2] Бецкий О.В., Кислов В.В., Лебедева Н.Н. Миллиметровые волны и живые системы. М.: Сайенс-пресс, 2004. 272 с.

[3] Петросян В.И., Синицын Н.И., Елкин В.А., Девятков Н.Д., Бецкий О.В. // Биомедицинская радиоэлектроника. 2000. № 2. С. 4-9.

[4] Кузнецов Д.Б. // Фундаментальные исследования. 2012. № 10 (часть 2). С. 400-404.

[5] Мищук Н.А. // Химия и технология воды. 2011. Т. 33. № 4. C. 353-366.

[6] Гильберт Л. Физическая теория живой клетки. Незамеченная революция (Пер. с англ.) 2008. 376 с.

[7] Петросян В.И. // Письма в ЖТФ. 2005. Т. 31. Вып. 23. C. 29-33. [Petrosyan V.I. // Tech. Phys. Lett. 2005. Vol. 31. N 12. P. 1007-1008.]

[8] Синицын Н.И., Елкин В.А. // Биомедицинская радиоэлектроника. 2007. № 2-4. С. 31-43.

[9] Хахалин А.В., Теплухин А.В. // Биомедицинская радиоэлектроника. 2006. № 1-2. С. 70-74.

[10] Концевой Ю.А., Литвинов Ю.М., Фаттахов Э.А. Пластичность и прочность полупроводниковых материалов и структур. М.: Радио и связь, 1982. 240 с.

[11] Тетельбаум Д.И., Тихов С.В., Курильчик Е.В., Менделева Ю.А. // ФТП. 2012. Т. 46. Вып. 5. С. 641-643. [Tetelbaum D.I., Tikhov S.V., Kuril'chik E.V., Mendeleva Y.A. // Semiconductors. 2012. Vol. 46. N 5. P. 622-624. DOI: $10.1134 / \mathrm{S} 1063782612050235]$ 
[12] Козловский В.В., Левшунова В.Л., Питиримова Е.А., Похил Г.П., Тетельбаум Д.И. // Поверхность. Рентгеновские, синхронные и нейтронные исследования. 2014. № 11. C. 82-85. DOI: $10.7868 /$ S0207352814110080 [Kozlovsky V.V., Levshunova V.L., Pitirimova E.A., Pokhil G.P., Tetelbaum D.I. // J. Surf. Investigation: X-Ray, Synchrotron and Neutron Techniques. 2014. Vol. 8. N 6. C. 1165-1167. DOI: $10.1134 / \mathrm{S} 1027451014060081]$

[13] Левшунова В.Л., Похил Г.П., Тетельбаум Д.И., ЧерHых П.Н. // Поверхность. Рентгеновские, синхротронные и нейтронные исследования. 2010. № 4. С. 9193. [Levshunova V.L., Pokhil G.P., Tetel'baum D.L., Chernykh P.N. // J. Surf. Investigation: X-Ray, Synchrotron and Neutron Techniques. 2010. Vol. 4. N 2. P. 350-352. DOI: $10.1134 / \mathrm{S} 102745101002031 \mathrm{X}$

[14] Тетельбаум Д.И., Азов Ю.А. // Вестник ННГУ. Сер. Физика твердого тела. 2001. Вып. 2 (5). С. 120-130.

[15] Тетельбаум Д.И., Курильчик Е.В., Менделева Ю.А. // Поверхность. Рентгеновские, синхротронные и нейтронные исследования. 2009. № 3. C. 94-103. [Tetelbaum D.I., Kuril'chik E.V., Mendeleva Y.A. // J. Surf. Investigation: XRay, Synchrotron and Neutron Techniques. 2009. Vol. 3. N 2. P. 249-258. DOI: 10.1134/S1027451009020153]

[16] Tetelbaum D.I., Azov A.Yu., Kuril'chik E.V., Bayankin V.Ya., Gilmutdinov F.Z., Mendeleva Yu.A. // Vacuum. 2003. Vol. 70. P. 169-173. DOI: 10.1016/S0042-207X(02)00637-1

[17] Тетельбаум Д.И., Курильчик Е.В., Менделева Ю.А., Пяткина А.A. // Поверхность. Рентгеновские, синхротронные и нейтронные исследования. 2013. № 7. C. 31-36. DOI: $10.7868 / \mathrm{S} 0207352813070196$ [Tetelbaum D.I., Kuril'chik E.V., Mendeleva Y.A., Pyatkina A.A. J. Surf. Investigation: X-Ray, Synchrotron and Neutron Techniques. 2013. Vol. 7. N 4. P. 631-636. DOI: $10.1134 / \mathrm{S} 1027451013040198]$

[18] Тетельбаум Д.И., Менделева Ю.А., Азов А.Ю. // Письма в ЖТФ. 2004. Т. 30. Вып. 11. C. 59-65. [Tetelbaum D.I., Mendeleva Yu.A., Azov A.Yu. // Tech. Phys. Lett. 2004. Vol. 30. N 6. P. 471-473. DOI: $10.1134 / 1.1773339]$

[19] Диденко А.Н., Шаркеев Ю.П., Козлов Э.В., Рябчиков А.И. Эффекты дальнодействия в ионно-имплантированных металлических материалах. Томск: Изд-во НТЛ, 2004. 328 с.

[20] Левшунова В.Л., Похил Г.П., Тетельбаум Д.И. // Поверхность. Рентгеновские, синхротронные и нейтронные исследования. 2011. № 3. С. 76-79. [Levshunova V.L., Pokhil G.P., Tetel'baum D.I. // J. Surf. Investigation: X-Ray, Synchrotron and Neutron Techniques. 2011. Vol. 5. N 2. P. 276-278. DOI: 10.1134/S1027451011030141]

[21] Такер Джс., Рэмптон В. Гиперзвук в физике твердого тела. М.: Мир, 1975. 453 с.

[22] Степанов А.В., Тетельбаум Д.И. // Поверхность. Рентгеновские, синхронные и нейтронные исследования. 2017. № 7. C. 82-88. DOI: $10.7868 /$ S0207352817070125 [Stepanov A.V., Tetelbaum D.I. // J. Surf. Investigation: X-Ray, Synchrotron and Neutron Techniques. 2017. Vol. 11. N 4. P. 756-761. DOI: $10.1134 / \mathrm{S} 1027451017040127$

[23] Takagi K., Negishi K. // Jpn. J. Appl. Phys. 1975. Vol. 4. N 7. P. 953-959. DOI: $10.1143 / J J A P .14 .953$

[24] Алехин В.П. Физика прочности и пластичности поверхностных слоев материалов. М.: Наука, 1983. 280 с.

[25] Dannefaer S., Mascher P., Kerr D. // Phys. Rev. Lett. 1986. Vol. 56. P. 2195-2198. DOI: 10.1103/PhysRevLett.56.2195

[26] Годжсиев Н.М. Оптика. М.: Высшая школа, 1977. 432 с. 